\title{
LOS LIBROS ÁLBUM RADICALES EN CONTEXTOS EDUCATIVOS: UNA REVISIÓN SISTEMÁTICA SOBRE PROPÓSITOS, COMPETENCIAS Y RELACIONES ENTRE MEDIADORES Y LECTORES
}

\author{
Radical Picture Books in Educational Settings: A Systematic Revision of Aims, \\ COMPETENCES, AND THE Relations Between MEdiators ANd READERS
}

LES LIVRES ALBUM RADICAUX EN CONTEXTE ÉDUCATIF : UNE RÉVISION SYSTÉMATIQUE SUR LES BUTS, LES COMPÉTENCES ET LES RAPPORTS ENTRE MÉDIATEURS ET LECTEURS

OS LIVROS ÁLBUM RADICAIS EM CONTEXTOS EDUCACIONAIS: UMA REVISÃO SISTEMÁTICA SOBRE PROPÓSITOS, COMPETÊNCIAS E AS RELAÇÕES ENTRE MEDIADORES E LEITORES

\section{Soledad Véliz}

Profesora asistente e investigadora asociada, Pontificia Universidad Católica de Chile, Santiago, Chile. sdveliz@uc.cl

https://orcid.

org/0000-0001-7143-420X

\begin{abstract}
RESUMEN
A pesar de las expectativas que han generado los libros radicales, no se ha sistematizado el aporte de estos respecto a sus propósitos, las competencias que promueven en los lectores y las interacciones que abren entre mediadores de la lectura (adultos) y lectores infantiles y juveniles. Este artículo pretende llenar este vacío presentando una revisión bibliográfica sistemática de 36 artículos empíricos que reúnen evidencia sobre el trabajo que se está llevando a cabo con libros álbum agrupados bajo la denominación de "radicales" en contextos educativos. Se entiende por "libros radicales" aquellos libros álbum que contiene una sofisticación narrativa (libros postmodernos), temáticas poco convencionales para la literatura infantil (inquietantes) y una producción editorial crossover o para todas las edades. El análisis categorial inductivo revela tres aspectos importantes: a) que los libros radicales son apreciados por producir brechas entre imagen y texto, lo que promueve la construcción de significado diverso en los lectores; b) que la investigación en esta área se enfoca en la promoción de competencias socioemocionales y de literacidad crítica, y c) que el uso de estos libros puede abrir relaciones más simétricas entre mediadores y lectores.
\end{abstract}

Palabras clave: competencias lectoras; libros radicales; libros álbum; mediadores; literatura infantil; lectores.

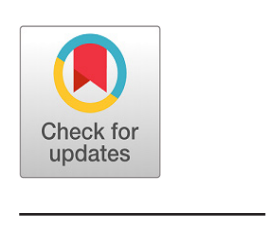

Recibido: 2021-05-03 / Aceptado: 2021-09-20 / Publicado: 2022-02-11

https://doi.org/10.17533/udea.ikala.v27n1a10

Editora: Doris Correa, Universidad de Antioquia, Medellín, Colombia.

Derechos patrimoniales, Universidad de Antioquia, 2022. Este es un artículo en acceso abierto, distribuido según los términos de la licencia Creative Commons BY-NC-SA 4.0 Internacional. 


\begin{abstract}
Despite the expectations that radical books have generated, contributions addressing their purposes, the skills they promote in readers, and the interactions they facilitate between reading mediators (adults) and child and youth readers have not been systematized. To fill this gap, this article presents a systematic bibliographic review of 36 empirical articles that gather evidence on the work carried out with picture books grouped under the label of "radical" in educational contexts. "Radical books" are picture books that have some narrative sophistication (postmodern books), present themes that are unconventional in children's literature (disturbing) and are crossover or for all ages. The categorical inductive analysis reveals three important aspects: (a) that radical books are valued for their opening of gaps between picture and text, thus promoting the construction of diverse meaning in readers; (b) that research in this area focuses on the promotion of socio-emotional and critical literacy skills, and (c) that their use can open more symmetrical relationships between mediators and readers.
\end{abstract}

Keywords: reading skills; radical books; picture books; mediators; children's literature; readers.

\title{
RÉSUMÉ
}

Malgré les attentes suscitées par les livres radicaux, des articles analysant leurs finalités, les compétences qu'ils promeuvent chez les lecteurs, et les interactions qu' ils ouvrent entre médiateurs de la lecture (adultes) et lecteurs enfants et jeunes n’ont pas été systématisés. Cet article est une revue bibliographique systématique de 36 articles empiriques qui rassemblent des témoignages sur le travail en contexte éducatif avec des livres album regroupés sous la catégorie de « radicaux ». Je propose la dénomination de « livres radicaux » pour ces livres-albums qui contiennent une sophistication narrative (livres postmodernes), des thèmes non conventionnels pour la littérature de jeunesse (dérangeants) et une production éditoriale crossover, ou pour tous les âges. Nous avons arrivés à trois conclusions : a) que les livres radicaux sont prisés pour produire des écarts entre l'image et le texte, ce qui favorise la construction d'un sens diversifié chez les lecteurs ; b) que la recherche dans ce domaine se concentre sur la promotion des compétences en littératie socio-émotionnelle et critique, et c) que leur utilisation peut encourager des relations plus symétriques entre les médiateurs et les lecteurs.

Mots clef : compétences lectrices; livres radicaux; livres album; mediateurs; littérature d'enfance; lecteurs.

\section{RESUMO}

Apesar das expectativas geradas pelos livros radicais, as contribuições que analisam seus propósitos, as habilidades que promovem nos leitores e as interações que abrem entre mediadores da leitura (adultos) e leitores infantis e juvenis não tem sido ainda sistematizados. Este artigo é uma revisão bibliográfica sistemática de 36 artigos empíricos que reúnem evidências sobre o trabalho em contextos educacionais com livros-álbum agrupados sob o nome de "radicais". Proponho a denominação de "livros radicais" para aqueles livros-álbum que contêm uma sofisticação narrativa (livros pós-modernos), temas não convencionais para a literatura infantil (perturbadores) e uma produção editorial cruzada ou para todas as idades. Temos chegado a três conclusões principais: a) que os livros radicais são apreciados por produzirem lacunas entre imagem e texto, o que promove a construção de um significado diverso nos leitores; b) que a pesquisa nesta área 
tem se concentrado na promoção de competências de literacia socioemocional e crítica, e c) que a sua utilização possa gerar relações mais simétricas entre mediadores e leitores.

Palavras chave: competências lectoras; livros radicais; livros-álbum; mediadores; literatura infantil; leitores. 


\section{Introducción}

Dentro de la literatura infantil se encuentran los libros álbum, un género literario en el que el significado es construido mediante la interacción de imagen y texto (Anstey y Bull, 2000). La codependencia narrativa de estos dos modos semióticos es lo que diferencia el libro álbum de otras producciones que usan imágenes (Nikolajeva y Scott, 2006). Por ejemplo, los libros álbum se configuran por una "brecha", un espacio imaginativo que yace entre las palabras y las imágenes donde se produce la narrativa (Watson y Styles, 1996). Por su parte, los libros ilustrados incluyen imágenes, pero estas no necesariamente co-construyen la narrativa con el texto. La importancia teórica de los libros álbum ha aumentado en las últimas décadas, así como su presencia como un recurso para la lectura y la enseñanza de la literatura en espacios escolares (Serafini, 2003).

La investigación ha explorado, principalmente, las competencias que los libros álbum promueven. Entre los dominios relevantes se encuentran habilidades asociadas al currículo, como el razonamiento sobre el mundo natural (Waxman et al., 2014), la teoría de la mente (Lysaker y Arvelo, 2016), las capacidades cognitivas (Riggio y Cassidy, 2009), el desarrollo de competencias literarias (Van der Pol, 2012), la literacidad inicial (Lysaker y Hopper, 2015), la adquisición del inglés (Belinda y Sierschynski, 2015) y la lectura y la escritura (Martens et al., 2012). A su vez, habilidades como literacidad visual, dominio artístico (O’Neil, 2011; Pantaleo, 2015; Styles y Arizpe, 2004) y transferencia de conocimiento desde la ficción al mundo real (Walker et al., 2015) han sido menos investigadas.

Como muestra el párrafo anterior, la investigación en contextos educacionales se ha centrado en el uso del libro álbum como recurso para apoyar la adquisición de habilidades relevantes para la escolaridad, pero se ha problematizado escasamente los propósitos de los libros álbum fuera de la lógica curricular y, de ser así, qué otras habilidades pueden promover.

La teoria del cambio radical, enunciada por Dresang (2008), propone que la literatura infantil y juvenil, aproximadamente desde los años noventa del siglo $\mathrm{Xx}$, ha sido sometida a diferentes cambios: en el formato, en los contenidos y en las audiencias. Nuevos libros, en particular álbumes, han surgido en esta lógica de innovación. Estos libros álbum posmodernos se caracterizan por la subversión de tradiciones literarias, la intertextualidad explícita, y alto grado de ambigüedad y no resolución (Sipe y McGuire, 2006). Por su parte, los libros álbum crossover (para todas las edades) se resisten a temáticas polarizadas por edad (Sipe y Pantaleo, 2008), y se caracterizan por dirigirse a audiencias duales o extendidas (Beckett, 1999, 2012). Por último, en relación con el contenido, se encuentran los libros álbum con temáticas literarias controversiales, poco convencionales o inquietantes (Nodelman, 2015). Estos libros tienen el potencial de canalizar las preocupaciones filosóficas y existenciales de la infancia, y presentan oportunidades ficticias para explorar temas complejos, dolorosos u oscuros (Beckett, 2012).

A efectos prácticos, se le llamará "radicales" al conjunto de libros álbum posmodernos, crossover e inquietantes. Libros álbum radicales sigue la definición ofrecida por Dresang (2008), quien considera a este conjunto de libros como aquellos con el potencial de desafiar las concepciones tradicionales del lector, la lectura y la mediación para la infancia.

Es relevante indagar en libros álbum radicales, debido a los intereses que estos han generado en el campo de la literatura infantil. Por ejemplo, se espera que estos libros condicionen las respuestas de los lectores, a fin de proveerlos con estrategias para subvertir las convenciones de la narrativa y desarrollar lectores más críticos (Evans, 2015), o que permitan el desarrollo de nuevas literacidades (Beckett, 2016). Existen expectativas optimistas relativas a la interacción entre mediadores y 
lectores con estos libros. Por ejemplo, se ha argumentado que este tipo de textos confirma una continuidad entre infancia y adultez, y la posibilidad de involucrarse en diálogos más honestos e igualitarios con lectores de diversas edades (Harju, 2012). Por último, su introducción supone una orientación hacia la infancia como una agente creadora de significado y una invitación a expandir las posibilidades epistémicas de la educación (Murris, 2015b; Whitelaw, 2017). De este modo, la incorporación de la literatura radical en contextos educativos tendría el potencial de enriquecer la concepción tradicional de lectura y, de paso, la relación entre mediadores y lectores, a partir de las conversaciones posibles que este tipo de libros facilita (Maagerø y Østbye, 2012; Murris, 2014). No obstante, estos supuestos se mantienen inexplorados a través de una revisión sistemática de investigaciones empíricas.

En resumen, la mayoría de las investigaciones sobre los libros álbum no distinguen entre las temáticas y las estrategias narrativas de estos, sino que se enfocan en las competencias que los libros podrían desarrollar. Un foco en los libros álbum radicales podría contribuir a entender cómo es usada la literatura infantil que desafía los estándares editoriales y aquellos asociados a la edad. Por otro lado, la mayoría de los estudios se refiere a habilidades asociadas al currículo, lo que produce brechas de investigación respecto a los propósitos y las competencias que podrían promover los libros álbum radicales fuera de esta lógica. Por último, las expectativas de que los libros álbum radicales contribuyan a relaciones más participativas y asimétricas entre mediadores y lectores no se han examinado.

Todo lo anterior representa una oportunidad para una línea de indagación sobre las relaciones entre la lectura y literatura radical en el contexto escolar. No obstante, para esto, es necesario comprender cómo la investigación en el campo de la literatura infantil hasta la fecha concibe los propósitos de la literatura radical, cuáles son las competencias de los lectores ante estos libros y qué indica la investigación empírica respecto de la interacción entre mediador y lector. El presente escrito propone abordar esta brecha en la investigación, mediante una revisión sistemática bibliográfica, entendida como la sistematización de hallazgos de diversos estudios, de modo de informar un campo particular (Ridley, 2012)-

\section{Método}

El foco de la presente revisión bibliográfica sistemática son los propósitos de los libros, las competencias promovidas en los lectores y las interacciones entre mediadores y lectores con libros álbum radicales.

\section{Recolección de datos}

Se llevaron a cabo varias búsquedas en inglés en las bases de datos de Web of Science (WoS) y Scopus. Estas bases incorporan investigaciones indexadas en revistas especializadas en educación, lo cual asegura un mínimo de calidad de la información presente en los artículos. No se determinó límite de años y se buscaron palabras clave presentes en el título y en los resúmenes.

Se realizaron dos búsquedas en cada base de datos. La primera contuvo las palabras clave: picturebook o picturebooks o picture book o picture books excluyendo e-book, digital y electronic junto a disquieting o challenging o crossover o post-modern o philosophical o radical. Esta búsqueda arrojó 103 resultados en WoS y 72 resultados en Scopus. En la segunda búsqueda se utilizaron las mismas palabras clave, más "critical literacy" o "enquiry" o "reader response" o "philosophy" o "philosophical'. La segunda búsqueda arrojó 125 resultados en WoS y 12 resultados en Scopus. Con los 312 artículos totales obtenidos en las cuatro búsquedas, se procedió a aplicar los criterios de exclusión e inclusión.

Uno de los objetivos de la revisión es entender cómo se usa un conjunto particular de libros álbum 
definidos como radicales. Para resolver esto, se usó como criterio de inclusión los estudios que consideran a los lectores como grupo de interés, empíricos, es decir, que usan una muestra de niños, niñas, jóvenes y adultos, y que ocurren en un contexto educativo formal. Los criterios de exclusión se aplicaron a partir de la lectura del título y del resumen.

La mayor cantidad de artículos excluidos corresponde a estudios que no tienen relación alguna con el tema de la revisión. Dado que esta revisión se centra en estudios que han indagado empíricamente en el tema, se excluyeron artículos teóricos (p. ej. Murris, 2015a) y otras revisiones sistemáticas de artículos como este escrito. Asimismo, se excluyeron aquellos estudios donde el foco no está en el libro ni en la relación con este, sino que estudian otras variables y el libro es solo un estímulo más (p. ej. Losh y Gordon, 2014). Un número significativo de estudios fue excluido por referirse a libros de texto (p. ej. Yang, 2016), a libros infantiles que no son libros álbum, como novelas (p. ej. Driscoll, 2013) o libros interactivos digitales que corresponden a un formato virtual (p. ej. Bus et al., 2015). Una cantidad menor de artículos no se encuentra publicado en inglés ( $p$. ej. BacholleBošković, 2009). Posteriormente a la aplicación de los criterios de exclusión e inclusión se obtuvieron 36 artículos. El artículo más antiguo es de 1995 y el más actual es del 2017.

\section{Análisis de los datos}

Una vez definido el corpus de estudio, se procedió al análisis. La mayoría de los estudios se enfocan en población infantil y juvenil, y seis estudios se enfocan en adultos. Un estudio se enfoca en ambos.

A través de un análisis categorial inductivo de las investigaciones seleccionadas, se proponen tres ejes para organizar esta revisión, con base en las preguntas de investigación de la revisión: los propósitos de este tipo de libros en contextos educativos, las competencias que estos libros promueven de acuerdo con las investigaciones revisadas y, por último, conceptualizar las relaciones entre mediador y lector en el marco de la lectura radical. En la Tabla 1 se resumen los estudios abordados por categorías de análisis.

Tabla 1 Resumen de artículos por categorías de análisis

\begin{tabular}{|c|c|}
\hline Categorías de análisis & Estudios \\
\hline \multirow{19}{*}{$\begin{array}{l}\text { Propósitos de la } \\
\text { literatura }\end{array}$} & Bartholomaeus (2015) \\
\hline & Crawley et al. (2012) \\
\hline & Evans (2016) \\
\hline & Harris y McKenzie (2005) \\
\hline & Hayik (2011, 2015) \\
\hline & Haynes y Murris (2013) \\
\hline & Hope (2016) \\
\hline & $\operatorname{Kim}(2014,2015,2016 a, 2016 b$, \\
\hline & $2016 c)$ \\
\hline & Korteweg et al. (2010) \\
\hline & Kuo (2009) \\
\hline & Lazar y Offenberg (2011) \\
\hline & Lysaker y Tonge (2013) \\
\hline & Maizonniaux (2017) \\
\hline & Murris y Ranchod (2015) \\
\hline & Murris y Thompson (2016) \\
\hline & Pantaleo (2010) \\
\hline & Prior et al. (2012) \\
\hline & Unsworth y Macken-Horarik (2015) \\
\hline \multirow{20}{*}{$\begin{array}{l}\text { Competencias de los } \\
\text { lectores }\end{array}$} & Crawley et al. (2012) \\
\hline & Dedeoglu et al. (2012) \\
\hline & Evans (2016) \\
\hline & Hardstaff (2014) \\
\hline & Hayik $(2011,2015)$ \\
\hline & Haynes y Murris (2013) \\
\hline & Hope (2016) \\
\hline & $\operatorname{Kim}(2014,2015,2016 a, 2016 b$, \\
\hline & $2016 c)$ \\
\hline & Korteweg et al. (2010) \\
\hline & Kuo (2009) \\
\hline & Lazar y Offenberg (2011) \\
\hline & Lysaker y Tonge (2013) \\
\hline & Maizonniaux (2017) \\
\hline & Murris y Ranchod (2015) \\
\hline & Murris y Thompson (2016) \\
\hline & Pantaleo $(2010,2017)$ \\
\hline & Prior et al. (2012) \\
\hline & Styles y Arizpe (2001) \\
\hline & Unsworth y Macken-Horarik (2015) \\
\hline
\end{tabular}


Tabla 1 Resumen de artículos por categorías de análisis (Cont.)

\begin{tabular}{ll}
\hline Categorías de análisis & \multicolumn{1}{c}{ Estudios } \\
\hline & Apol et al. (2002) \\
& Bartholomaeus (2015) \\
& Crawley et al. (2012) \\
& Daugaard y Johansen (2014) \\
& Dedeoglu et al. (2012) \\
& Evans (2016) \\
& Harris y McKenzie (2005) \\
& Hayik (2011, 2015) \\
& Haynes y Murris (2013) \\
& Hope (2016) \\
& Kim (2014, 2016a, 2016b, 2016c) \\
& Korteweg et al. (2010) \\
& Kuo (2009) \\
& Lysaker y Tonge (2013) \\
& Maizonniaux (2017) \\
& Mantei (2015) \\
Relaciones entre & Murris y Ranchod (2015) \\
mediadores y lectores & Murris y Thompson (2016) \\
& Pantaleo (2004a, 2004b, 2010, 2016) \\
& Prior et al. (2012) \\
& Serafini (2005) \\
& Smith (1995) \\
& Styles y Arizpe (2001) \\
& Unsworth y Macken-Horarik (2015) \\
\hline & \\
\hline &
\end{tabular}

\section{Resultados}

A continuación se mostrarán los resultados organizados en relación a las categorías de propósitos de los libros álbum radicales, competencias de los lectores y relaciones entre mediadores y lectores que las investigaciones dicen que son promovidas por estos libros.

\section{Propósitos de los libros álbum radicales en contextos educativos}

La primera pregunta tiene que ver con los propósitos del libro álbum en contextos educativos. Dentro de esta, emergen las categorías del libro álbum como modelo y el libro álbum como gatillante (véase Tabla 2).

\section{El libro álbum como modelo}

De Marzio (2011) propone que los textos pueden usarse como objetos que contienen una descripción esquemática de un fenómeno: un modelo. Este permitiría influenciar el pensamiento, las actitudes, los valores y las conductas de los lectores. Aun así, el texto se posiciona como una autoridad que porta el significado, de modo que el propósito de su uso se relaciona con cuánto los lectores se desvían del significado presente en el texto.

Los propósitos descritos por la investigación que usa los libros álbum como modelo son muy variados. No obstante, es posible identificar algunos modelos. El más escaso corresponde a modelos para la creación. Pantaleo (2010) ofrece un estudio en el que los libros álbum son usados como un

Tabla 2 Artículos divididos por propósitos de la literatura

\begin{tabular}{|c|c|}
\hline $\begin{array}{l}\text { Foco en los } \\
\text { propósitos }\end{array}$ & Estudios \\
\hline \multirow{9}{*}{ Libros como modelo } & Bartholomaeus (2015) \\
\hline & Harris y McKenzie (2005) \\
\hline & Hope (2016) \\
\hline & $\operatorname{Kim}(2014,2016 a, 2016 c)$ \\
\hline & Lysaker y Tonge (2013) \\
\hline & Maizonniaux (2017) \\
\hline & Pantaleo (2010) \\
\hline & Prior et al. (2012) \\
\hline & Unsworth y Macken-Horarik (2015) \\
\hline \multirow{12}{*}{ Libros como gatillante } & Apol et al. (2002) \\
\hline & Crawley et al. (2012) \\
\hline & Evans (2016) \\
\hline & Hayik (2011, 2015) \\
\hline & Haynes y Murris (2013) \\
\hline & Hope (2016) \\
\hline & $\operatorname{Kim}(2016 b)$ \\
\hline & Korteweg et al. (2010) \\
\hline & Kuo (2009) \\
\hline & Lazar y Offenberg (2011) \\
\hline & Murris y Ranchod (2015) \\
\hline & Murris y Thompson (2016) \\
\hline
\end{tabular}


esquema o estructura sobre el cual los estudiantes deben basarse para crear sus propias historias.

Otros estudios lo conforman aquellos que usan los libros como modelo de significados (Prior et al., 2012; Unsworth y Macken-Horarik, 2015), es decir, las respuestas de los lectores son juzgadas en relación con el significado del texto, el que se concibe como repositorio del significado correcto u oficial.

Algunos estudios se sirven de los libros como modelo de la realidad (Harris y McKenzie, 2005; Lysaker y Tonge, 2013). Harris y McKenzie (2005) conciben a libros álbum que muestran múltiples perspectivas e intertextualidad como un modelo para explicarles a los lectores infantiles y juveniles cómo la realidad está construida. De manera similar, Lysaker y Tonge (2013) usan la literatura infantil como un modelo vicario de relaciones interpersonales que es posible extender a las relaciones humanas.

Por último, algunos estudios esperan usar el libro para influenciar al lector. Los estudios de esta revisión son empleados para promover cambios en la valoración y la percepción de los lectores, por ejemplo, respecto a los roles de género (Bartholomaeus, 2015; Kim, 2014, 2016a, 2016c), actitudes positivas hacia inmigrantes (Hope, 2016), hacia la literatura infantil (Maizonniaux, 2017) y para modelar respuestas emocionales adecuadas (Lysaker y Tonge, 2013).

\section{El libro álbum como gatillante}

Esta categoría agrupa investigaciones donde se afirma que el propósito del libro álbum es promover la creación de significado por parte de los lectores, los que pueden desviarse del supuesto contenido explícito del libro. Es decir, esta categoría describe procesos por los cuales los lectores pueden diferenciarse de la autoridad del libro para crear significados propios.

Dentro de esta categoría es posible identificar diversos propósitos: desde experiencias y vivencias de los lectores, así como entornos socioculturales y políticos. De este modo, en primer lugar, algunos estudios usan los libros como un medio para referir a las experiencias y vivencias que los lectores "traen" a la lectura (Crawley et al., 2012; Hayik, 2011; Hope, 2016; Kim, 2016b). Crawley et al. (2012), por ejemplo, usan libros álbum con estudiantes de enfermería para plantear la temática de la muerte, la que promueve la reflexión crítica de las experiencias, las vivencias, los valores y las actitudes de estos.

En segundo lugar, un grupo de estudios (Apol et al., 2002; Hayik, 2011, 2015; Korteweg et al., 2010; Kuo, 2009; Lazar y Offenberg, 2011) se sirven de los libros álbum para movilizar a los lectores a reflexionar más allá de sus experiencias personales, sobre problemas políticos y sociales de las comunidades en donde viven, o sobre problemas filosóficos (Evans, 2016). Una de las formas de lograr esto es que los lectores construyan el significado "en contra" del mensaje intencionado del texto. Por ejemplo, Hayik (2015) invita a estudiantes árabes a reescribir cuentos de hadas que contienen estereotipos de género, para deconstruir perspectivas tradicionales sobre femineidad y el rol de la mujer en la cultura árabe.

Por lo tanto, en esta categoría, los libros son usados como un punto de partida para la construcción de significado, el cual se concibe como parte de una compleja matriz de relaciones entre el texto situado social, política e históricamente, la experiencia y los conocimientos de los individuos. En estos casos, el significado no se encuentra en el texto, sino en el espacio entre el texto y los lectores (Rosenblatt, 1993).

\section{Competencias que promueven los libros} álbum radicales en contextos educativos

La intención de esta pregunta es dar cuenta del tipo de competencia que, según los estudios analizados, es beneficiada mediante la lectura de libros álbum radicales. Se ofrecen las subcategorías de competencias afectivas y socioemocionales, comprensión lectora, alfabetización visual y competencias críticas y subversivas (véase Tabla 3). 
Tabla 3 Artículos divididos por competencias de los lectores

\begin{tabular}{ll}
\hline \multicolumn{1}{c}{ Competencias } & \multicolumn{1}{c}{ Estudios } \\
\hline & Crawley et al. (2012) \\
& Evans (2016) \\
& Hardstaff (2014) \\
& Haynes y Murris (2013) \\
& Hope (2016) \\
& Kim (2014, 2015, 2016a, 2016b, 2016c) \\
Afectivas y & Kuo (2009) \\
socioemocionales & Lysaker y Tonge (2013) \\
& Maizonniaux (2017) \\
& Murris y Thompson (2016) \\
& Prior et al. (2012) \\
& Styles y Arizpe (2001) \\
& Lysaker y Tonge (2013) \\
& Pantaleo (2010) \\
\hline \multirow{2}{*}{ Comprensión lectora } & Pantaleo (2010, 2016) \\
& Prior et al. (2012) \\
& Styles y Arizpe (2001) \\
& Unsworth y Macken-Horarik (2015) \\
\hline Alfabetización visual & Crawley et al. (2012) \\
& Dedeoglu et al. (2012) \\
& Hayik (2011, 2015) \\
& Haynes y Murris (2013) \\
& Hope (2016) \\
& Kim (2014, 2016a, 2016b, 2016c) \\
& Korteweg et al. (2010) \\
& Kuo (2009) \\
& Lazar y 0ffenberg (2011) \\
& Murris y Ranchod (2015) \\
& Murris y Thompson (2016) \\
& Pantaleo (2016) \\
\hline & \\
&
\end{tabular}

\section{Estudios que reportan competencias afectivas y socioemocionales}

Los estudios que indican que los libros álbum radicales apuntan a competencias afectivas y socioemocionales relevan la relación entre el lector y los personajes, y documentan las reacciones emocionales de los lectores ante aspectos estéticos y visuales de las narrativas.

Varios estudios reportan cómo los lectores se involucran emocional y afectivamente con los personajes de las narrativas, siendo la empatía una de las reacciones socioemocionales más reportada por los investigadores (Evans, 2016; Hope, 2016; Kim, 2014; Murris y Thompson, 2016).

Algunos estudios sitúan el involucramiento afectivo en características de los libros, como la presencia de múltiples perspectivas, las que promoverían la identificación emocional con los personajes (Evans, 2016; Hope, 2016; Kim, 2014). Otros estudios se centran en cómo los lectores responden afectivamente ante elementos visuales como el color (Prior et al., 2012; Styles y Arizpe, 2001).

\section{Estudios de comprensión lectora}

Un grupo de estudios reporta respuestas asociadas a la comprensión lectora, a partir de intervenciones basadas en el desarrollo de competencias lectoras (Daugaard y Johansen, 2014; Lysaker y Tonge, 2013) y narrativas (Pantaleo, 2010). Si bien los estudios de esta categoría suelen reportar beneficios, Lysaker y Tonge (2013) es la única investigación que respalda, con una estrategia metodológica clara, las declaraciones de mejora en competencias narrativas y comprensión oral.

Otra de las competencias reportadas es la metalingüística. Pantaleo (2010) reporta, como producto de varias sesiones de instrucción, la adquisición de metalenguaje sobre dispositivos metaficcionales. La autora asocia la adquisición de mayor vocabulario sobre las estructuras narrativas de libros posmodernos con mayor capacidad de comprensión y competencia narrativa.

En conclusión, la menor parte de los estudios revisados tienen que ver con la adquisición de competencias de comprensión lectora y narrativas, y las metodologías de evaluación utilizadas son, en su mayoría, cualitativas.

\section{Estudios sobre alfabetización visual}

Uno de los aspectos relevantes de los libros álbum es que el significado se construye con base en la interacción de imágenes y palabras. No obstante, 
algunos estudios revisados se concentran en el código visual de estos, en particular en el aporte a la alfabetización visual por parte del color, la línea y el simbolismo. Por ejemplo, Styles y Arizpe (2001) registran cómo los estudiantes interpretan los estilos artísticos y el uso simbólico del color.

Otros estudios asocian la comprensión de significados emocionales y la comprensión de elementos visuales (Pantaleo, 2015; Prior et al., 2012). Unsworth y Macken-Horarik (2015) ofrecen una forma de evaluar el uso del metalenguaje sobre los aspectos visuales de los libros álbum, de modo que describen los propósitos o efectos de las decisiones de autores e ilustradores.

En resumen, los estudios de respuesta sobre literacidad visual se sobreponen, hasta cierto punto, con los estudios sobre respuestas afectivas, pero se enfocan en el aporte de la capacidad de lectura de elementos visuales.

\section{Estudios que reportan respuestas} criticas y subversivas

La mayoría de los estudios de esta revisión reportan respuestas asociadas con el pensamiento crítico y de tipo subversivas. Las respuestas de pensamiento crítico suelen referirse a procesos reflexivos de los lectores que permiten a los investigadores asumir que los estudiantes están argumentando de forma crítica (Crawley et al., 2012; Korteweg et al., 2010). Por otro lado, muchos estudios reportan respuestas creativas de los estudiantes como evidencia de que estos han llegado a un nivel más avanzado de habilidades críticas, ya que la creación es considerada como la subversión del contenido de los libros (Ko, 2013; Hayik, 2011, 2015; Hope, 2016; Kim, 2014, 2016b; Murris y Thompson, 2016).

Entre los estudios que reportan pensamiento crítico, dos de ellos informan sobre respuestas que reflejan pensamiento autorreflexivo (Crawley et al., 2012; Korteweg et al., 2010). Crawley et al. (2012) afirman que las respuestas de los lectores en su estudio evidencian secuenciación, análisis y síntesis de información, componentes de la autorreflexión llevada a cabo acerca de las preconcepciones sobre la muerte de los propios lectores.

Muchos de estos estudios suelen desprenderse del marco teórico de literacidad crítica de Lewison et al. (2002) y Lewison et al. (2008). Hayik (2011, 2015), Hope (2016) y Kuo (2009) declaran que los estudiantes de sus estudios exhiben respuestas críticas de acuerdo con las siguientes dimensiones: interrupción de los lugares comunes (al hacer dibujos que critican lo normalizado en los libros), consideración de múltiples puntos de vista (al ponerse en el lugar de los personajes), proveer respuestas que trascienden las experiencias personales para enfocarse en aspectos sociopolíticos (al criticar relaciones de poder e injusticia) y, finalmente, promover la justicia social (al incorporar en sus respuestas posicionamientos contra la injusticia). Otras investigaciones documentan de forma similar, pero solo toman una o dos dimensiones de los marcos establecidos de literacidad crítica (Kim, 2014, 2016a, 2016c).

Por último, varios estudios informan respuestas que evidencian pensamiento crítico a través de la crítica a las respuestas de otros lectores (Haynes y Murris, 2013; Murris y Ranchod, 2015), como aquellos afiliados al programa de Filosofía para Niños (P4C) fundado por Matthew Lipman.

Una declaración que surge en varios de los estudios es que el pensamiento crítico se logra y expresa por medio de respuestas creativas, en particular con la creación de narrativas subversivas o "en contra" del texto (Hayik, 2011, 2015; Hope, 2016; Kim, 2014, 2016b; Murris y Thompson, 2016). Por ejemplo, Murris y Thompson (2016) reportan la creación de finales alternativos, mediante los cuales los niños y las niñas subvierten el significado intencionado del libro álbum y las interpretaciones de los adultos. Por lo tanto, las respuestas críticas están relacionadas con cuestionar o reflexionar acerca de los propios sentimientos, actitudes, valores y creencias, leer en forma crítica, o interrogarse por el significado del texto y las respuestas que otros dan a este. 
Por último, un nivel máximo de habilidad crítica se logra, según los estudios, cuando los estudiantes son capaces de responder creativamente ante los textos.

\section{Relaciones entre mediadores y lectores durante las lecturas con libros álbum radicales}

Por último, esta revisión está interesada en documentar la interacción entre mediadores y lectores durante la lectura de libros álbum radicales. Cuatro categorías emergen al tratar de responder a esta pregunta: el mediador como observador, como autoridad, como facilitador y como cuestionador (véase Tabla 4).

\section{El mediador como observador de las interacciones entre lector y libro}

En primer lugar, un conjunto de estudios se caracteriza por identificar al mediador como un sujeto de la interacción que facilita las condiciones básicas para que se produzca la lectura y la creación de significado. Este rol se ha denominado "observador", por cuanto se abstiene de participar activamente en la producción de significado. Entre las funciones de los mediadores, se encuentra la lectura en voz alta del libro (p. ej. Bartholomaeus, 2015), la organización del espacio físico de la lectura, y la administración y la organización de las respuestas de los lectores (p. ej. Murris y Thompson, 2016). En algunos estudios, este rol es necesario para asegurar un entorno donde los estudiantes se organizan autónomamente para crear significado a partir de los libros (p. ej. Bartholomaeus, 2015; Dedeoglu et al., 2012; Hayik, 2011; Maizonniaux, 2017). En la mayoría de los estudios, los observadores cumplen un rol estable durante toda la investigación; no obstante, en algunas publicaciones, los observadores solo lo son en una etapa específica de esta (Hayik, 2011; Korteweg et al., 2010).

\section{El mediador como autoridad epistémica y axiológica}

En segundo lugar, hay estudios que instalan al mediador como una autoridad epistémica o
Tabla 4 Artículos divididos por categorías que describen la interacción entre mediadores y lectores

\begin{tabular}{|c|c|}
\hline $\begin{array}{l}\text { Foco en la } \\
\text { interacción }\end{array}$ & Estudios \\
\hline Mediador como & Bartholomaeus (2015) \\
\hline \multirow[t]{6}{*}{ observador } & Dedeoglu et al. (2012) \\
\hline & Hayik (2011, 2015) \\
\hline & Haynes y Murris (2013) \\
\hline & Korteweg et al. (2010) \\
\hline & Maizonniaux (2017) \\
\hline & Murris y Thompson (2016) \\
\hline Mediador como & Apol et al. (2002) \\
\hline \multirow[t]{2}{*}{ autoridad } & $\operatorname{Kim}(2014,2015,2016 a, 2016 b, 2016 c)$ \\
\hline & Pantaleo $(2010,2016)$ \\
\hline Mediador como & Daugaard y Johansen (2014) \\
\hline \multirow[t]{11}{*}{ facilitador } & Evans (2016) \\
\hline & Hope (2016) \\
\hline & Kuo (2009) \\
\hline & Lysaker y Tonge (2013) \\
\hline & Mantei (2015) \\
\hline & Murris y Ranchod (2015) \\
\hline & Pantaleo (2004a, 2004b) \\
\hline & Serafini (2005) \\
\hline & Smith (1995) \\
\hline & Styles y Arizpe (2001) \\
\hline & Unsworth y Macken-Horarik (2015) \\
\hline Mediador como & Crawley et al. (2012) \\
\hline \multirow[t]{4}{*}{ cuestionador } & Harris y McKenzie (2005) \\
\hline & $\operatorname{Kim}(2014,2016 a, 2016 c)$ \\
\hline & Pantaleo (2007) \\
\hline & Prior et al. (2012) \\
\hline
\end{tabular}

propietario del significado del libro, y juez de las respuestas de los lectores (Apol et al., 2002; Pantaleo, 2010, 2016), o como autoridad axiológica acerca de lo que es correcto o incorrecto pensar y sentir a propósito de la lectura (Kim, 2014, 2016a, 2016b, 2016c).

En comparación con la categoría anterior, el mediador como autoridad participa invasivamente de la creación del significado, al modelar las respuestas de los lectores. Por ejemplo, Pantaleo (2016) muestra a un mediador como evaluador de las respuestas de los estudiantes, por lo general en intervenciones con objetivos pedagógicos. Por otro lado, el 
mediador como autoridad axiológica es particularmente evidente en una serie de estudios que usan las conversaciones de profesores con estudiantes jóvenes (Kim, 2014, 2016a, 2016b, 2016c). En estos estudios son comunes los diálogos en los que los profesores identifican conductas y actitudes deseables, y las comunican explícitamente a los lectores. Kim (2016c) reporta cómo una profesora, al hablar sobre estereotipos de género con sus estudiantes, hace juicios de valor en defensa de un personaje que no se comporta como los estudiantes esperan.

En conclusión, el mediador como autoridad epistémica es un rol que surge en estudios con objetivos pedagógicos definidos. Asimismo, en estudios con niños y niñas y jóvenes, se suele configurar como una autoridad valórica.

\section{El mediador como facilitador de las respuestas de los lectores}

210 El tercer rol es el de facilitador de la relación entre libros álbum y lectores. Este conjunto de estudios sitúa al mediador como una presencia prevalente durante el proceso de lectura, en particular en la interacción entre el libro y el lector, hasta el momento en que se obtienen las respuestas. Una vez que el lector responde, sin embargo, el facilitador se retrae.

Los facilitadores que suscitan respuestas, lo hacen a través de preguntas cuidadosamente diseñadas para ese fin, en oposición a entregar explícitamente información sobre el texto, y suelen usar el marco Chambers (1993), como Daugaard y Johansen (2014), Evans (2016), Lysaker y Tonge (2013), Mantei (2015) y Pantaleo (2004b).

Otros estudios conciben a los facilitadores como guías que tutelan la lectura y la creación de significado sobre aspectos potencialmente problemáticos de los libros. Lo anterior se observa en la lectura de libros álbum sobre emociones (Murris y Ranchod, 2015), con complejidad o sofisticación visual (Pantaleo, 2007; Serafini, 2005; Styles y Arizpe,
2001; Unsworth y Macken-Horarik, 2015), o con temáticas consideradas provocadoras (Hope, 2016; Kuo, 2009).

En Hope (2016), la autora describe las sesiones de lectura en voz alta como una instancia en que los profesores les "dan voz" a los textos que leen, llenan las brechas de significado en lugar del lector y filtran partes no deseadas de la historia. Otra tarea de los facilitadores, descrita en la literatura se ejemplifica en Pantaleo (2004a), estudio en el cual la investigadora hace preguntas que guían la atención de los estudiantes hacia aspectos ignorados del texto, como: ¿qué está haciendo este personaje?¿por qué está haciendo ese movimiento? o ¿notaste algo extraño?

\section{El mediador como cuestionador de las respuestas de los lectores}

Un posicionamiento menos común, pero igual de relevante, es el mediador como cuestionador. Este rol se caracteriza por contrastar, contrapreguntar y criticar las respuestas de los lectores. Por ejemplo, Prior et al. (2012) establecen un rol de facilitador usando preguntas como: “¿qué ves en esta ilustración?, para luego moverse al rol de cuestionador con preguntas como: ¿cómo sabes? o ¿qué pistas en el libro te ayudan a pensar eso?” (p. 199).

Como en otros roles ya discutidos, estos no son estables a lo largo de toda la intervención. Es el caso de $\operatorname{Kim}$ (2016a, 2016c), que ha reportado posicionamiento de los mediadores de sus estudios como autoridad; también entrega evidencia de los mismos profesores en el rol de cuestionadores. En el caso ya presentado de la profesora que trabaja con estereotipos de género con sus estudiantes, esta usa preguntas para movilizar las actitudes de los lectores; por ejemplo: “ipiensas que ella (el personaje de la historia) es una mala niña porque no le gusta cocinar ni limpiar?" (Kim, 2016c, p. 15). Si bien la mediadora luego hace una intervención que la sitúa en un rol de autoridad sobre lo que es 
correcto acerca de los roles de género, en su papel de cuestionadora propone preguntas que desafían las respuestas iniciales de los estudiantes.

Para finalizar, los hallazgos sobre el mediador como cuestionador configuran un rol didáctico y movilizador, que busca empujar y expandir el proceso de construcción de significado mediante la confrontación crítica de las respuestas de los lectores.

\section{Discusión}

En esta revisión de 36 artículos empíricos se pretendió presentar una panorámica del campo de la investigación sobre libros álbum radicales en torno a los propósitos, las competencias de los lectores y la relación entre lectores y mediador. Esta revisión de literatura propone diferentes categorías para entender la importancia y el rol de la literatura radical en contextos educativos, los que se resumen y discuten a continuación.

\section{¿De qué son capaces los libros radicales?}

En esta revisión se etiquetó a un conjunto de libros álbum con palabras clave como "posmoderno", "crossover" e "inquietante", con el supuesto de que todos eran libros álbum radicales según lo definición ya dada de Dresang (2008). Producto de esta revisión, se evidenció que esta es una etiqueta enormemente variada, que incluye temáticas como muticulturalidad, feminismo y diversidad de género, muerte, enfermedad y emociones. En la Tabla 5 se muestra la lista de libros álbum radicales reportados por estudio.

Asimismo, la etiqueta "libros álbum" es muy variada en cuanto al uso de dispositivos literarios como la intertextualidad y la transtextualidad (Harris y McKenzie, 2005), así como libros cuyos autores pertenecen a una comunidad particular, como indígenas (Korteweg et al., 2010) o afroamericanos (Gardner, 2016; Lazar y Offenberg, 2011).

No toda esta literatura toma su nombre del objeto libro, es decir, un libro se considera radical no solo por ser de una temática desafiante o contar con ciertos dispositivos literarios. Literatura como la de cuentos de hadas es también etiquetada como desafiante al ser utilizada en el marco de una intervención de literacidad crítica (Kim, 2014), lo que

Tabla 5 Lista de libros álbum radicales reportados por estudio

\begin{tabular}{l|l}
\hline \multicolumn{1}{c|}{ Libros reportados y fechas de publicación } & \multicolumn{1}{c}{ Estudios } \\
\hline An Undone Fairytale (Lender y Martin, 2005) & Pantaleo (2010) \\
Chester (Watt, 2007) & \\
Wolves (Gravett, 2005) & Pantaleo (2004a) \\
\hline A Day at Damp Camp (Lyon, 1996) & \\
The Three Pigs (Wiesner, 2001) & \\
\hline Safari (Bateman, 1998) & \\
Shortcut (Macaulay, 1995) & \\
Snowflake Bentley (Martin, 1998) & Pantaleo (2004b) \\
Something From Nothing (Gilman, 1992) & \\
The Empty Pot(Demi, 1990) & \\
The Three Pigs (Wiesner, 2001) & \\
Tuesday (Wiesner, 1991) & \\
Voices in the Park (Browne, 1998) & \\
Willy the Dreamer (Browne, 1997) & \\
\hline The Three Pigs (Wiesner, 2001) & Pantaleo (2010) \\
Tuesday (Wiesner, 1991) & \\
Voices in the Park (Browne, 1998) \\
Willy the Dreamer (Browne, 1997)
\end{tabular}


Tabla 5 Lista de libros álbum radicales reportados por estudio (Cont.)

\begin{tabular}{|c|c|}
\hline Libros reportados y fechas de publicación & Estudios \\
\hline $\begin{array}{l}\text { Chester (Watt, 2007) } \\
\text { Flotsam (Wiesner, 2006) } \\
\text { Interrupting Chicken (Stein, 2010) } \\
\text { No Bears (McKinlay y Rudge, 2012) } \\
\text { The Three Pigs (Wiesner, 2001) } \\
\text { Tuesday (Wiesner, 1991) } \\
\text { Voices in the Park (Browne, 1998) }\end{array}$ & Pantaleo (2015) \\
\hline $\begin{array}{l}\text { Draw (Colón, 2014) } \\
\text { Flotsam (Wiesner, 2006) } \\
\text { Interrupting Chicken (Stein, 2010) } \\
\text { Mr. Tiger Goes Wild (Brown, 2013) } \\
\text { The Three Pigs (Wiesner, 2001) } \\
\text { This is a Moose (Morris y Lichtenheld, 2014) } \\
\text { Tuesday (Wiesner, 1991) }\end{array}$ & Pantaleo (2016) \\
\hline $\begin{array}{l}\text { The Great Bear (Gleeson y Greder, 1999) } \\
\text { The Tunnel(Browne, 1989) }\end{array}$ & $\begin{array}{l}\text { Unsworth y Macken- } \\
\text { Horarik (2015) } \\
\end{array}$ \\
\hline $\begin{array}{l}\text { Leonardo the Terrible Monster (2005) } \\
\text { Lilly's Purple Plastic Purse (1996) } \\
\text { When Sophie gets angry- really, really angry (1999) }\end{array}$ & Prior et al. (2012) \\
\hline The Waterhole (Base, 2001) & Harris y McKenzie (2005) \\
\hline $\begin{array}{l}\text { Dr. Martin Luther King, Jr. (Rappaport, 2001) } \\
\text { Fly Away Home (Bunting, 1991) } \\
\text { Ian's Walk: A Story About Autism (Lears, 1998) } \\
\text { Martin's Big Words: The Life of Martin Luther King Jr. } \\
\text { (Rappaport y Collier, 2001) } \\
\text { Shrinking Violet (Best, 2001) } \\
\text { Thank You, Mr. Falker (Polacco, 1998) } \\
\text { The Story of Ruby Bridges (Coles, 1995) }\end{array}$ & Lysaker y Tonge (2013) \\
\hline $\begin{array}{l}\text { A Fire Engine for Ruthie (Newman y Moore, 2004) } \\
\text { Cinder Edna (Jackson y O'Malley, 1994) } \\
\text { Piggybook (Browne, 1986) } \\
\text { William's Doll(Zolotow y Pène du Bois, 1972) }\end{array}$ & Bartholomaeus (2015) \\
\hline The colour of home (Hoffman, 2002) & Hope (2016) \\
\hline $\begin{array}{l}\text { 신데렐라(Cinderella) (2010) } \\
\text { 콩쥐팥쥐 (Kong-gee, Pot-gee) (2003) } \\
\text { 백설공주(Princess Snow White) (2001) } \\
\text { 아기돼지 삼형제 (Three little pigs) (2005) }\end{array}$ & $\operatorname{Kim}(2014)$ \\
\hline $\begin{array}{l}\text { Amazing Grace (Hoffman, 1991) } \\
\text { Chocolate Me! (Diggs, 2011) } \\
\text { Let's Talk about Race (Lester, 2005) } \\
\text { The bus's ride (Miller, 1998) } \\
\text { Tar Beach (Ringgold, 1991) } \\
\text { The Song of Freedom (Hung Kang, 2009) }\end{array}$ & $\operatorname{Kim}(2015)$ \\
\hline
\end{tabular}


Tabla 5 Lista de libros álbum radicales reportados por estudio (Cont.)

\begin{tabular}{|c|c|}
\hline Libros reportados y fechas de publicación & Estudios \\
\hline $\begin{array}{l}\text { Do Princesses Wear Hiking Boots? (Coyle, 2003) } \\
\text { The Paper Bag Princess (Munsch, 1980) } \\
\text { The Princess Knight(Funke, 2004) } \\
\text { What mommies do best/What daddies do best(Numeroff, 1998) }\end{array}$ & $\operatorname{Kim}(2016 a)$ \\
\hline $\begin{array}{l}\text { Colourful world (Winans y Thomas, 2010) } \\
\text { Do We Really Have That Kind of Race? (Roncaglia, 2000) } \\
\text { Let's Talk about Race (Lester, 2007) }\end{array}$ & $\operatorname{Kim}(2016 b)$ \\
\hline $\begin{array}{l}\text { Do Princesses wear Hiking Boots?(Coyle, 2003) } \\
\text { I Want to Be a Cowgirl (Willis, 2003) } \\
\text { The boy with pink hair (Hilton, 2011) } \\
\text { The Paper Bag Princess (Munsch, 2013) } \\
\text { William's doll(Zolotow, 1985) }\end{array}$ & $\operatorname{Kim}(2016 c)$ \\
\hline $\begin{array}{l}\text { John Chatterton Détective (Pommaux, 1993) } \\
\text { Le Chandail de Hockey (The Hockey Sweater) (Carrier, 1979) } \\
\text { Le Petit Chaperon Vert (Solotareff y Solotareff, 1989) } \\
\text { Pochée (Seyvos, 1994) } \\
\text { Reine (Delaunay, 2008) }\end{array}$ & Maizonniaux (2017) \\
\hline $\begin{array}{l}\text { Die Schopfung (The Creation) (Waechter, 2002) } \\
\text { Stormy Night (Lemieux, 1999) } \\
\text { The Big Question (Erlbruch, 2005) }\end{array}$ & Evans (2016) \\
\hline Feathers and Fools (Fox, 1989) & Hayik (2011) \\
\hline $\begin{array}{l}\text { Cinder Edna (Jackson, 1994) } \\
\text { Piggybook (Browne, 1986) }\end{array}$ & Hayik (2015) \\
\hline Tusk tusk (McKee, 1978) & Haynes y Murris (2013) \\
\hline $\begin{array}{l}\text { Caribou song (Highway, 2001) } \\
\text { Waboose's Morning on the lake (Bourdeau, 1997) }\end{array}$ & Korteweg et al. (2010) \\
\hline $\begin{array}{l}\text { A Picture Book of Anne Frank (Adler, 1993) } \\
\text { The Story of Ruby Bridges (Coles, 1995) }\end{array}$ & Kuo (2009) \\
\hline Little Beauty (Browne, 2008) & Murris y Ranchod (2015) \\
\hline The Big Ugly Monster and the Little Stone Rabbit(Wormell, 2004) & Murris y Thompson (2016) \\
\hline $\begin{array}{l}\text { Black Ants and Buddhists: Thinking Critically and Teaching } \\
\text { (Cowhey, 2006) } \\
\text { Differently in the Primary Grades (Cowhey, 2006) } \\
\text { From Slave Ship to Freedom Road (Lester, 1998) } \\
\text { Harriet and the Promised Land (Lawrence, 1997) } \\
\text { Dear Benjamin Banneker (Pinkney, 1994) }\end{array}$ & Lazar y Offenberg (2011) \\
\hline $\begin{array}{l}\text { Death, Duck and the Tulip (Erlbruch, 2008) } \\
\text { Sad Book (Rosen y Blake, 2004) }\end{array}$ & Crawley et al. (2012) \\
\hline Black and White (Macaulay, 1990) & Hardstaff (2014) \\
\hline Zoo (Browne, 1992) & Styles y Arizpe (2001) \\
\hline $\begin{array}{l}\text { The Great Bear (Greder y Gleeson, 1999) } \\
\text { The Tunnel(Browne, 1989) }\end{array}$ & $\begin{array}{l}\text { Unsworth y Macken- } \\
\text { Horarik (2015) }\end{array}$ \\
\hline $\begin{array}{l}\text { And Tango Makes Three (Parnell, Richardson y Cole, 2005) } \\
\text { Molly's Family (Garden y Wooding, 2004) }\end{array}$ & Dedeoglu et al. (2012) \\
\hline
\end{tabular}


Tabla 5 Lista de libros álbum radicales reportados por estudio (Cont.)

\begin{tabular}{l|l}
\hline \multicolumn{1}{c|}{ Libros reportados y fechas de publicación } & \multicolumn{1}{c}{ Estudios } \\
\hline Mirror (2010) & Mantei (2015) \\
\hline An exciting story (Glaz Serup y Thau-Jensen, 2009) & $\begin{array}{l}\text { Daugaard y Johansen } \\
\text { (2014) }\end{array}$ \\
\hline Voices in the Park (Browne, 1998) & Serafini (2005) \\
\hline Sadako (Coerr, 1993) & Apol et al. (2002) \\
\hline
\end{tabular}

sugiere que cualquier literatura podría, con el adecuado marco teórico, potencialmente desafiar cómo y qué se le lee a la infancia.

La etiqueta de "libros radicales" parece agrupar o referenciar a libros que son elegidos por la forma en que estos están construidos, en particular, por el modo particular en que usan la "brecha" entre imagen y texto (Evans, 2016; Murris y Ranchod, 2015; Murris y Thompson, 2016; Pantaleo, 2004a). En tales estudios, mientras menos concurrencia exhiban ambos modos semióticos, se asume que mayor es la incertidumbre respecto al significado, por ejemplo, en propósito de los libros como gatillante. De esta manera, se configura una relación entre propósito del uso del libro y tipo de texto, en la cual los libros más inciertos son más apreciados.

Ahora, ¿son más apreciados para qué procesos? La brecha entre imagen y texto, o la inestabilidad del significado es apreciada particularmente en libros que representan y narran procesos sociales o significados, de modo tal que visibilizan temáticas complejas que suelen estar invisibilizadas. La aparición de libros multiculturales dentro del grupo de libros radicales (Hayik, 2011; Lazar y Offenberg, 2011) y su uso para generar "diálogos difíciles” en el aula indica que el propósito de estos libros es introducir no solo temáticas a contextos educativos en los que, de otra manera, sería muy difícil incluirlas, sino también una forma de pensar sobre estas temáticas, promovida por la comunión de imagen y texto. De todas formas, llama la atención que la mayoría de las investigaciones usan los libros como "gatillantes".
En esta búsqueda de un lector con libertad para producir significado, los libros también son elegidos por la brecha entre imagen y texto (Styles y Arizpe, 2001). Esta valoración se reserva, comúnmente, a narrativas posmodernas, las que utilizan dispositivos metaficcionales que demandan una relación poco tradicional de involucramiento con los lectores (Daugaard y Johansen, 2014; Pantaleo, 2004b, 2010; Serafini, 2005; Styles y Arizpe, 2001).

Es importante que los libros radicales tengan ciertas características (en particular, una brecha extensa entre imagen y texto), lo que se asume como un facilitador para desafiar los significados autoritarios del texto. No obstante, su radicalidad no está dada por el dispositivo libro en aislamiento de su uso. Gran parte de la radicalidad de esta literatura está dada por cómo los lectores lidian con estos libros y cómo los docentes e investigadores los utilizan en contextos educativos.

\section{¿De qué son capaces los lectores?}

Gran parte de los estudios empíricos revisados invierten esfuerzos en demostrar la capacidad de los lectores de producir respuestas antes textos posmodernos, de temáticas complejas y perturbadoras. La cantidad de estudios dedicados a esta causa demuestran una intención reivindicatoria por parte de los investigadores de posicionar a los niños y las niñas como lectores sofisticados y capaces.

Efectivamente, el campo de investigación empírico de las respuestas de lector ha sido criticado 
por presentar una visión extremadamente optimista, casi ingenua, acerca de las capacidades de los niños, las niñas y los jóvenes (Beauvais, 2015; Flynn, 2014; Nodelman, 2013). La principal crítica se dirige a la proliferación de estudios acerca de niños, niñas y jóvenes que responden a textos de manera creativa y de formas optimistas y placenteras, en desmedro del reconocimiento de prácticas de literacidad crítica y respuestas incómodas que pueden producirse (Nodelman, 2013). En esta revisión, esto se evidencia en relación con los propósitos socioemocionales del estos libros: los lectores son posicionados como competentes para lidiar con emociones complejas y perturbadoras.

No obstante, este retrato de los niños y las niñas como lectores imperturbables se complica ante la evidencia que aportan los estudios de respuesta crítica, que si bien merecen un análisis más cuidadoso que el que se les da en esta sección, también configuran lectores que se involucran con los textos de forma ideológica, política y social. Los estudios de respuestas críticas no muestran lectores ni una infancia lectora complaciente y dispuesta a involucrarse en cualquier tipo de lectura, sino que resaltan la dimensión social, política, ideológica y cultural de la lectura, aspectos con los cuales los niños, las niñas y los jóvenes de los estudios se involucran, resisten y responden.

Los resultados muestran que, ante la lectura, los lectores pueden resistirse o involucrarse con los libros álbum radicales. Del total de 36 estudios, 13 reportan respuestas de resistencia. Los hallazgos de esta revisión dejan ver que la resistencia al involucramiento con los textos no es una conducta reportada solamente en niños, niñas y jóvenes, sino que también se presenta en los adultos mediadores o futuros mediadores. La Tabla 6 muestra las razones de la resistencia, reportadas en los estudios analizados.

Las razones que los estudios proponen como respuesta a esta resistencia, sin embargo, son distintas en ambos grupos etarios. En estudios de resistencia de niños, niñas y jóvenes, las razones se enfocan en las características y temáticas de los libros, pero también en las características de los lectores. Por ejemplo, Smith (1995) describe cómo un niño le cambia el sexo a un personaje para adecuarlo al estereotipo de género (que el libro está tratando de revertir). En el caso de los estudios de resistencia por parte de los adultos también se encuentran los libros y los lectores, pero aparecen como razones importantes las concepciones acerca de la infancia que estos tienen y cómo conciben el propósito de la educación. Si bien las respuestas de resistencia merecen un análisis por sí mismas, es arriesgado suponer que la resistencia se da ante el libro. La investigación empírica ha mostrado que la lectura se encuentra inmersa en intervenciones e interacciones complejas y continuas, que se extienden en el tiempo, e involucran diversas estrategias de interacción con los lectores. En tal contexto, es difícil separar al libro de la intervención. Solo dos estudios reportan disminución de la resistencia después de intervención (Kim, 2016a; Maizonniaux, 2017). Maizonniaux (2017) muestra cómo la resistencia de estudiantes adultos a leer libros álbum disminuye tras un semestre de trabajo con estos libros, y Kim (2016a) declara que los comentarios de género estereotipados de los niños, las niñas y los jóvenes disminuyen a medida que hay más sesiones de discusión con libros álbum que desafían estereotipos de género.

Dado el alto número de estudios que han reportado respuestas de resistencia y considerando que estas se dan en estudios con intervenciones simples (Bartholomaeus, 2015; Dedeoglu et al., 2012; Gardner, 2016; Maizonniaux, 2017; Mantei, 2015; Smith, 1995) y complejas (Apol et al., 2002; Serafini, 2005), esta representa un interesante área de indagación futura.

Por ahora, es relevante concluir con que los estudios empíricos acerca de la capacidad de los lectors y la resistencia representan polos distantes dentro del campo empírico de las teorías de respuesta 
Tabla 6 Detalle de las resistencias reportadas en los estudios

\begin{tabular}{|c|c|c|c|}
\hline & & Las resistencias & Estudios \\
\hline \multirow{10}{*}{$\begin{array}{l}\text { Grupo que } \\
\text { resiste }\end{array}$} & \multirow[t]{6}{*}{ Niños, niñas y jóvenes } & & Bartholomaeus (2015) \\
\hline & & & Gardner (2016) \\
\hline & & & Hardstaff (2014) \\
\hline & & & $\operatorname{Kim}(2014,2015,2016 a, 2016 b, 2016 c)$ \\
\hline & & & Serafini (2005) \\
\hline & & & Smith (1995) \\
\hline & \multirow[t]{4}{*}{ Adultos } & & Dedeoglu et al. (2012) \\
\hline & & & Harris y McKenzie (2005) \\
\hline & & & Lazar y Offenberg (2011) \\
\hline & & & Maizonniaux (2017) \\
\hline \multirow{16}{*}{$\begin{array}{l}\text { Tipo de } \\
\text { resistencia }\end{array}$} & \multirow{9}{*}{$\begin{array}{l}\text { Tipos de } \\
\text { resistencias en } \\
\text { todas las edades }\end{array}$} & Resistencia a leer o a aceptar libros que desafían valores & Bartholomaeus (2015) \\
\hline & & y actitudes tradicionales sobre etnia y género & Dedeoglu et al. (2012) \\
\hline & & & Gardner (2016) \\
\hline & & & Harris y McKenzie (2005) \\
\hline & & & $\operatorname{Kim}(2014,2015,2016 c)$ \\
\hline & & & Smith (1995) \\
\hline & & Resistencia a leer 0 a aceptar libros que desafían & Hardstaff (2014) \\
\hline & & narrativas lineales & Harris y McKenzie (2005) \\
\hline & & & Serafini (2005) \\
\hline & \multirow{5}{*}{$\begin{array}{l}\text { Razones de } \\
\text { resistencias en } \\
\text { niños, niñas y } \\
\text { jóvenes }\end{array}$} & Subjetividades culturales y raciales; resistencia a & Gardner (2016) \\
\hline & & representaciones racializadas & $\operatorname{Kim}(2015)$ \\
\hline & & Poco conocimiento intertextual previo de narrativas & Bartholomaeus (2015) \\
\hline & & que interrumpen la tradicionalidad del género; poca & $\operatorname{Kim}(2014 ; 2016 b ; 2016 c)$ \\
\hline & & $\begin{array}{l}\text { identificación con personajes; predominancia de } \\
\text { estereotipos de género }\end{array}$ & Smith (1995) \\
\hline & \multirow{2}{*}{$\begin{array}{l}\text { Tipos de resistencias } \\
\text { en adultos }\end{array}$} & Concepciones conservadoras de la infancia & Dedeoglu et al. (2012) \\
\hline & & Resistencia a leer en forma crítica & Lazar y Offenberg (2011) \\
\hline
\end{tabular}

del lector. Esta tensión no se halla resuelta en el terreno más amplio de estudios teóricos, y algunos autores la atribuyen a un problema con las fuentes disponibles que documentan las interacciones de los niños, las niñas y los jóvenes con los textos, las que, a su vez, se encuentran fuertemente mediadas por adultos e instituciones adultas. La siguiente discusión, por lo tanto, se centra en las relaciones entre mediadores y lectores.

\section{¿De qué son capaces los mediadores?}

Debido a la posición de los niños, las niñas y los jóvenes en la sociedad, uno de los usos de la literatura infantil es como vehículo didáctico por medio de los cuales estos son enculturados (Allan,
2015). Los textos infantiles no transmiten la cultura de manera simétrica, ya que representan principalmente los valores y las creencias de la clase media alta, con estrictos roles sociales y de género (Nodelman y Reimer, 2003).

Esta conceptualización de la literatura infantil como un sistema simbólico e ideológico diseñado para educar en los valores de los grupos dominantes (grupos que se considera son la norma o lo natural frente a comunidades que no se han plegado a narrativas avanzadas por las políticas públicas; por ejemplo, grupos indígenas que no hablan la "lengua oficial", niños en situación de discapacidad que no leen o se desempeñan académicamente como sus pares) está fuertemente enmarcada por la 
presencia del adulto (Enciso et al., 2010). Lo anterior constituye una línea de argumentación que ha defendido la imposibilidad de la literatura infantil sin la intervención adulta (Rose, 1984; Zipes, 2001), y que cuestiona el tipo de relación que se establece y es posible establecer en y a través de los textos literarios entre niños, niñas y jóvenes.

Lo anterior ha sido eficientemente condensado por Nikolajeva (2010) a través del concepto de aetonormatividad, o normatividad adulta impuesta en los textos. Este concepto concentra una construcción ideológica de la infancia y de las relaciones entre los niños, las niñas, los jóvenes y adultos desde el punto de vista de los últimos (Nikolajeva, 2010). No obstante, mucho del entusiasmo del campo teórico y empírico ante libros álbum inquietantes proviene de la posibilidad que estos representan de subvertir las relaciones aetonormativas que se dan en el contexto de la lectura compartida.

Esta sección es importante bajo la lógica de algunos autores que indican que, ante la dificultad de generar respuestas auténticas de los niños, las niñas y los jóvenes, es preferible analizar la forma en que los adultos "consciente e inconscientemente moldean las interacciones de aquellos con los libros" (Schwebel, en Flynn, 2014, p. 252).

Los resultados de esta revisión proponen cuatro roles que cumplen los mediadores en los estudios: observador, autoridad, facilitador y cuestionador. Lo primero que llama la atención es que no existe un rol del mediador como cocreador de significado, de modo que los estudios no reportan relaciones simétricas entre lectores y mediadores en la generación de significado. Los diversos estudios sitúan al mediador como más o menos importante para el logro de los objetivos de la investigación, y a los lectores, a diferentes niveles de dependencia del mediador para poder responder, pero nunca a un nivel donde el lector sea quien provea las condiciones para la lectura, o se conforme como una autoridad del significado. Es decir, por muy contemplativo que sea el rol del mediador, este no intercambia posición con los lectores.

La figura de mediador, por lo tanto, es siempre adulta, aunque los lectores en estos estudios pueden ser niños, niñas, jóvenes y adultos. Podría sugerirse que, por lo tanto, las relaciones de asimetría no se circunscriben solo a los niños, las niñas y los jóvenes. En este caso, la aetonormatividad es reemplazada por una especie de espacio de dominancia epistemológica del mediador, que surge en las lecturas en contextos educativos.

La relación directa de los mediadores con los libros se restringe a las siguientes: filtrar, modificar y andamiar significados que el propio mediador considera difíciles o complejos para los lectores, en especial cuando estos son niños, niñas y jóvenes (facilitador) o imponer la propia visión del significado de los libros (autoridad). El resto de las funciones de los mediadores están asociadas a relacionarse periféricamente con el libro, como preparar el espacio o enfocarse en las preguntas que hace el lector. De este modo, los estudios empíricos no suelen posicionar al mediador en una relación intercambiable con los lectores ni lo definen por su relación con el libro; por lo tanto, no es definido como un lector. La única vez que los mediadores en estos estudios son lectores es bajo el rol de autoridad, ya que, obviamente, tienen que haber leído el libro para imponer su perspectiva.

La relación entre el significado, el mediador y el lector en estas investigaciones se configura como una interacción, asimétrica y compleja. El mediador como observador y el mediador como facilitador tienen un grado de interferencia bajo a moderado en el proceso de construcción de significado de los lectores; por lo tanto, de relativa asimetría. El observador se retrae, muchas veces, con el objetivo de brindar a los lectores espacio para construir significado, como si la presencia del mediador implicara pérdida automática de libertad y autonomía de los lectores. De este modo, si bien este rol pretende generar instancias de coconstrucción de significado (p. ej. Murris 
y Ranchod, 2015; Murris y Thompson, 2016), los mediadores suelen desaparecer del proceso de significación. Así, los lectores pueden participar "libremente" de la relación con los libros, pero el mediador debe mantenerse al margen de toda participación en el proceso de construcción de significado.

Como facilitador, no obstante, el control se ejerce al comienzo de la intervención; pero una vez producida la respuesta, el mediador se debilita, como si el significado y la mediación se acabaran con la respuesta. Por otro lado, el mediador como autoridad y como cuestionador constituye altos grados de intromisión y contacto con los lectores y el significado; no obstante, al mismo tiempo, genera relaciones de naturaleza muy diferente. El mediador como autoridad representa explícitamente la aetonormatividad y las relaciones en el extremo más asimétrico de poder, mientras que el rol de cuestionador configura un nivel de mayor simetría, en el sentido de que, por medio de preguntas críticas, se acercan a la coconstrucción de significado. Por lo tanto, la investigación empírica revisada proporciona escasa evidencia de que la lectura con libros álbum radicales promueva relaciones simétricas entre mediadores y lectores. Con lo que sí contribuye es con una descripción de los roles en los que la investigación sitúa a los mediadores.

De este conjunto de investigaciones emerge una descripción tentativa de lo que se considera un mediador de este tipo de literatura: este es siempre un adulto, con un rol inestable a lo largo de las interacciones.

\section{Conclusiones}

En conclusión, con respecto a los propósitos, la denominación de "libros álbum radicales" contiene una amplia diversidad de textos, y ha demostrado ser extremadamente maleable a los propósitos y objetivos de cada investigación.

Acerca de las apreciaciones iniciales que motivaron esta revisión, aun cuando los libros son usados como gatillantes, el tipo de libro es importante; no obstante, la etiqueta de "radical" no ha demostrado ser particularmente coherente con las características definidas teóricamente: posmoderno, escatológico o crossover, sino por otras características, como la "brecha" entre imagen y texto.

Respecto a los hallazgos de respuestas de los lectores, Beauvais (2015) describe una tensión entre el campo teórico de investigación de libros infantiles, el que sostiene que los libros son instrumentos ideológicos de socialización y aetonormatividad, y el campo empírico de respuesta del lector, que se caracteriza por investigaciones afirmativas.

No obstante, esta revisión revela un conjunto de estudios empíricos que no son optimistas. Es más, en esta revisión, la tensión está entre los estudios empíricos de respuestas de capacidad y el resto, especialmente estudios de resistencia y respuestas críticas. Esta tensión se refleja en dos modelos esencialistas de infancia: el "niño inocente" y el “niño que sabe”. En el primero, la infancia es retratada como inocente, en necesidad de protección y naturalmente bondadosa (Sánchez-Eppler, 2011), mientras que, en el segundo, los niños y las niñas son conscientes de las amenazas y los deseos presentes en el mundo, pero aún merecen la protección adulta (Sánchez-Eppler, 2011).

Las concepciones sobre la infancia suelen promover diferentes supuestos sobre cuáles son las historias más apropiadas para contarles a los niños y las niñas (Sánchez-Eppler, 2011). De modo que no es raro que la concepción del "niño inocente" justifique una posición social pasiva y condescendiente, que convierte a estos en receptáculos de temáticas inocentes y simples (Rudd, 2004).

Estas dos visiones, y otras, configuran diferentes tipos de lectores y, por lo tanto, de infancia. Estas formas dicotómicas de ver "al niño" requieren urgentemente de moderación y actualización, a través de estudios que investiguen las respuestas de resistencia y respuestas críticas en profundidad. Por lo tanto, con relación a las expectativas mencionadas en la introducción a esta revisión, los estudios sobre la lectura de estos libros representan 
la oportunidad de configurar un lector complejo, difícil de categorizar.

Una de las razones para introducir libros álbum radicales al contexto escolar es que estos suponen una orientación hacia la infancia como una agente creadora de significado y una invitación para expandir las posibilidades epistémicas de los estudiantes y profesores y, por lo tanto, de la educación (Maagerø y Østbye, 2012; Murris, 2014). Sin embargo, la aetonormatividad se manifiesta en varios hallazgos discutidos anteriormente, de manera primordial en las relaciones asimétricas entre lectores y mediadores.

Estudios que usan un marco de literacidad crítica, no obstante, han mostrado potencial de movilizar las relaciones entre mediadores y lectores hacia una mayor simetría de las relaciones. El rol que los estudios de literacidad les atribuyen a los mediadores se enfoca en provocar discusiones que promuevan el análisis crítico de las respuestas propias y de otros. De este modo, a través de la interpelación, los mediadores también se involucran en el proceso de creación de significado, si bien desde el rol de generar preguntas claves. Por lo tanto, de acuerdo con las expectativas que motivaron esta revisión, la lectura de libros inquietantes no moviliza relaciones automáticas de simetría entre lectores y adultos.

Para finalizar, esta revisión propone varias áreas de investigación en el campo de los estudios empíricos. La primera es la relación entre propósitos de lectura y características de los libros. Las conclusiones de este trabajo sugieren que los libros son siempre utilizados por alguna de sus características radicales, aunque la misma definición de este término sea ambigua.

La segunda es el beneficio que pueden obtener los estudios empíricos en la incorporación de conceptos y avances del campo teórico de la investigación en literatura infantil. En esta lógica, los libros nunca son ingenuos ni inocentes. Asimismo, esta revisión detectó otra tensión en el campo empírico, esta vez entre estudios positivos de capacidad de respuesta y estudios críticos y de resistencia de los lectores. Mayor investigación en esta temática contribuiría a configurar un lector de estos libros que no sea posible abarcar con definiciones esencialistas.

En tercer lugar, hay mucho por investigar respecto a los roles que los mediadores adquieren durante la lectura de este tipo de libros, especialmente en relación con los mediadores que contribuyen a establecer relaciones de simetría.

\section{Referencias}

Allan, C. (2015). Towards an analysis of the utilisation of metafictive strategies in postmodern picturebooks. English in Australia, 50, 35-38. https://eprints.qut. edu.au/96281/

Anstey, M. y Bull, G. (2000). Reading the visual: Written and illustrated children's literature. Harcourt.

Apol, L., Sakuma, A., Reynolds, T. M. y Rop, S. K. (2002). "When can we make paper cranes?": Examining pre-service teachers' resistance to critical readings of historical fiction. Journal of Literacy Research, 34(4), 429-464. https://doi.org/10.1207/ s15548430jlr3404_3

Bacholle-Bošković, M. Auteurs de jeunesse franco-maghrébins: un modèle d'intégration ? 36, 65-74. https:// doi.org/10.1007/s1 1059-009-1007-z

Bartholomaeus, C. (2015). "Girls can like boy toys": Junior primary school children's understandings of feminist picture books. Gender and Education, 28(7), 935-950. https://doi.org/10.1080/09540253.2015 .1106443

Beauvais, C. (2015). The mighty child: Time and power in children's literature. John Benjamins. https://doi. org/10.1075/clcc.4

Beckett, S. (1999). Transcending boundaries: Writing for a dual audience of children and adults. Garland Publishing Inc.

Beckett, S. (2012). Crossover picturebooks: A genre for all ages. Routledge. https://doi.org/10.4324/9780203154038

Beckett, S. (2016). Common ground for children and adults: Picturebooks for philosophers of all ages. Keimena, (32), 1-12. http://keimena.ece.uth.gr/ main/index.php?option $=$ com_content $\& v i e w=a r-$ ticle\&id=346:22-beckett \&catid=66:-22\&Ite$\operatorname{mid}=102$ 
Belinda, L. y Sierschynski, J. (2015). Enhancing English learners' language development using wordless picture books. Reading Teacher, 69(1), 103-111. https:// doi.org/10.1002/trtr.1376

Bus, A., Takacs, G., Zsofia, K. y Kegel, C. A. T. (2015). Affordances and limitations of electronic storybooks for young children's emergent literacy. Developmental Review, 35, 79-97. https://doi.org/10.1016/j. dr.2014.12.004

Cohen, L., Manion, L. y Morrison, K. (2011). Research methods in education. Routledge.

Crawley, J., Ditzel, L. y Walton, S. (2012). Using children's picture books for reflective learning in nurse education. Contemporary Nurse, 42(1), 45-52. https://doi. org/10.5172/conu.2012.42.1.45

Chambers, A. (1993). Tell me. Children reading and talk. Thimble Press.

Daugaard, L. M. y Johansen, M. B. (2014). Multilingual children's interaction with metafiction in a postmodern picture book. Language and Education, 28(2), 120-140. https://doi.org/10.1080/09500782.2013.786085

De Marzio, D. M. (2011). What happens in philosophical texts: Matthew Lipman's theory and practice of the philosophical text as model. Childhood \& Philosophy, 7(13), 29-47. https://www.redalyc.org/ pdf/5120/512051603003.pdf

Dedeoglu, H., Ulusoy, M. y Lamme, L. L. (2012). Turkish preservice teachers' perceptions of children's picture books reflecting LGBT-related issues. Journal of Educational Research, 105(4), 256-263. https://doi.org/ $10.1080 / 00220671.2011 .627398$

Dresang, E. T. (2008). Radical change theory, postmodernism and contemporary picturebooks. In L. Sipe y S. Pantaleo (Eds.), Postmodern picturebooks: Play, paro$d y$, and self-referentiality (pp. 41-54). Routledge.

Driscoll, B. (2013). Using Harry Potter to teach literacy: Different approaches. Cambridge Journal of Education, 43(2), 259-271. https://doi.org/10.1080/030 5764X.2013.784241

Dunne, M., Pryor, J. y Yates, P. (2005). Becoming a researcher. A research companion for the social sciences. Open University Press.

Enciso, P., Wolf, S., Coats, K. y Jenkins, C. (2010). Children's literature: Standing in the shadow of adults. Reading Research Quarterly, 45(2), 252-263. https://doi. org/10.1598/RRQ.45.2.5

Evans, J. (2015) Picturebooks as strange, challenging and controversial texts. In J. Evans (Ed.). Challenging and controversial picturebooks. Creative and critical responses to visual texts (pp. 1-32). Routledge.

Evans, J. (2016). Who am I? Why am I here? and Where do I come from? Responding to philosophical picturebooks. Education, 44(1), 53-67. https://doi.org/10. $1080 / 03004279.2015 .1109815$

Flynn, R. (2014). Introduction: Disputing the role of agency in children's literature and culture. In C. L. A. (ChLA) (Ed.), Children's agency: A panel discussion on divergent critical models (Vol. 8, Jeunesse: Young People, Texts, Cultures series). Panel "Children's agency: A panel discussion on divergent critical models", organizado por la Children's Literature Association (ChLA), University of South Carolina, 18 de junio.

Gardner, R. P. (2016). Unforgivable blackness: Visual rhetoric, reader response, and critical racial literacy. Children's Literature in Education, 48, 119-133. https://doi.org/10.1007/s10583-016-9291-5

Goldstone, B. P. (2002). Whaz up with our books? Changing picture book codes and teaching implications. The Reading Teacher, 55(2002), 362-370. https:// www.jstor.org/stable/20205063

Hardstaff, S. (2014). "Maybe he's on the toy train": Empathizing and systematising in an encounter with David Macaulay's Black and White. Literacy, 48(2), 80-85. https://doi.org/10.1111/lit.12033

Harju, M. L. (2012). "Being not alone in the world". Exploring reader responses to crossover books. McGill University.

Harris, P. y McKenzie, B. (2005). Networking around The Waterhole and other tales: The importance of relationships among texts for reading and related instruction. Literacy, 39(1), 31-37. https://doi. org/10.1111/j.1741-4350.2005.00395.x

Hayik, R. (2011). Critical visual analysis of multicultural sketches. English Teaching-Practice and Critique, 10(1), 95-118. https://files.eric.ed.gov/fulltext/ EJ935565.pdf

Hayik, R. (2015). Diverging from traditional paths: Reconstructing fairy tales in the EFL classroom. Diaspora, Indigenous, and Minority Education, 9(4), 221-236. https://doi.org/10.1080/15595692.2015.1044084

Haynes, J. y Murris, K. (2013). The realm of meaning: Imagination, narrative and playfulness in philosophical exploration with young children. Early Child Development and Care, 183(8), 1084-1100. https://doi. org/10.1080/03004430.2013.792256

Hope, J. (2016). “The soldiers came to the house": Young children's responses to The Colour of Home. Children's 
Literature in Education, 49, 302-322. https://doi. org/10.1007/s10583-016-9300-8

Kim, S. J. (2014). Possibilities and challenges of early critical literacy practices: Bilingual preschoolers' exploring multiple voices and gender roles. Journal of Early Childhood Research, 14(4), 370-388. https://doi. org/10.1177/1476718X14552878

Kim, S. J. (2015). Korean-origin kindergarten children's response to African-American characters in race-themed picture books. Education Research International, 1, 1-13. https://doi. org/10.1155/2015/986342

Kim, S. J. (2016a). Expanding the horizons for critical literacy in a bilingual preschool classroom: Children's responses in discussions with gender-themed picture books. International Journal of Early Childhood, 48, 311-327. https://doi.org/10.1007/ s13158-016-0171-3

Kim, S. J. (2016b). Opening up spaces for early critical literacy: Korean kindergarteners exploring diversity through multicultural picture books. Australian Journal of Language and Literacy, 39(2), 176-187. https://search.informit.org/doi/10.3316/ aeipt. 218961

Kim, S. J. (2016c). "Pink is a girl's color": A case study of bilingual kindergarteners' discussions about gender roles. Critical Inquiry in Language Studies, 13(4), 237-260. https://doi.org/10.1080/15427587.2016 .1163494

Ko, M-Y. (2013). A case study of an EFL teacher's critical literacy teaching in a reading class in Taiwan. Language Teaching Research, 17(1), 91-108. https://doi. org/10.1177/1362168812457537

Korteweg, L., Gonzalez, I. y Guillet, J. (2010). The stories are the people and the land: Three educators respond to environmental teachings in Indigenous children's literature. Environmental Education Research, 16(3-4), 331-350. https://doi. org/10.1080/13504620903549755

Kuo, J.-M. (2009). Critical literacy and a picturebook-based dialogue activity in Taiwan. Asia Pacific Education Review, 10, 483. https://doi. org/10.1007/s12564-009-9048-6

Lazar, A. M. y Offenberg, R. M. (2011). Activists, allies, and racists: Helping teachers address racism through picture books. Journal of Literacy Research, 43(3), 275 313. https://doi.org/10.1177/1086296X11413720

Lewison, M., Flint, A. S. y Van Sluys, K. (2002). Taking on critical literacy: The journey of newcomers and novices.
Language Arts, 79(5), 382-392. https://www.jstor. org/stable/41483258

Lewison, M., Leland, C. y Harste, J. C. (2008). Creating critical classrooms: K-8. Reading and writing with an edge. Lawrence Erlbaum. https://doi. org/10.4324/9780203826317

Losh, M. y Gordon, P. C. (2014). Quantifying narrative ability in autism spectrum disorder: A computational linguistic analysis of narrative coherence. Journal of Autism and Developmental Disorders, 44, 30163025. https://doi.org/10.1007/s10803-014-2158-y

Lundin, A. (2004). Constructing the canon of children's literature. Beyond library walls andivory towers. Routledge. https://doi.org/10.4324/9780203312940

Lysaker, J. y Arvelo, Z. (2016). Theorizing fiction reading engagement during wordless book reading. Linguistics and Education, 37, 42-51. https://doi. org/10.1016/j.linged.2016.11.001

Lysaker, J. y Hopper, E. (2015). A kindergartner's emergent strategy use during wordless picture book reading. Reading Teacher, 68(8), 649-657. https://doi. org/10.1002/trtr.1352

Lysaker, J. y Tonge, C. (2013). Learning to understand others through relationally oriented reading. The Reading Teacher, 66(8), 632-641. https://doi.org/10.1002/ trtr. 1171

Maagerø, E. y Østbye, G. L. (2012). Do worlds have corners? When children's picture books invite philosophical questions. Children's Literature in Education, 43, 323-337. https://doi.org/10.1007/ s10583-012-9166-3

Maizonniaux, C. (2017). Australian university students reading francophone picturebooks-An original study. Bookbird: A Journal of International Children's Literature, 55(1), 24-32. https://doi.org/10.1353/ bkb.2017.0003

Mantei, J. (2015). Examining the interpretations children share from their reading of an almost wordless picture book during independent reading time. Australian Journal of Language and Literacy, 38, 183-192. https://ro.uow.edu.au/cgi/viewcontent.cg $\mathrm{i}$ ? article $=2942 \&$ context $=$ sspapers

Martens, P., Martens, R., Hassay, M. Loomis, J. y Aghalarov, S. (2012). Learning from picturebooks: Reading and writing multimodally in first grade. The Reading Teacher, 66(4), 285-294. https://doi.org/10.1002/ TRTR.01099

Murris, K. (2014). Reading philosophically in a community of enquiry: Challenging developmentality with 
Oram and Kitamura's Angry Arthur. Children's Literature in Education, 45, 145-165. https://doi. org/10.1007/s10583-013-9205-8

Murris, K. (2015a). Posthumanism, philosophy for children, and Anthony Browne's "Little beauty." Bookbird: A Journal of International Children's Literature, 53(2), 59-65. https://doi.org/10.1353/bkb.2015.0030

Murris, K. (2015b). The philosophy for children curriculum: Resisting "teacher proof" texts and the formation of the ideal philosopher child. Studies in Philosophy and Education, 35, 63-78. https://doi. org/10.1007/s11217-015-9466-3

Murris, K. y Ranchod, V. (2015). Opening up a philosophical space in early literacy with Little Beauty by Anthony Browne and the movie King Kong. Reading \& Writing, 6(1), 1-10. https://doi.org/10.4102/ rw.v6i1.69

Murris, K. y Thompson, R. (2016). Drawings as imaginative expressions of philosophical ideas in a Grade 2 South African literacy classroom. Reading and Writing. Journal of the Reading Association of South Africa, 7(2), 1-11. https://doi.org/10.4102/rw.v7i2.127

Nikolajeva, M. (2010). Power, voice and subjectivity in literature for young readers. Taylor and Francis. https:// doi.org/10.4324/9780203866924

Nikolajeva, M. y Scott, C. (2006). How picturebooks work. Routledge.

Nodelman, P. (2008). The hidden adult: Defining children's literature. John Hopkins University Press.

Nodelman, P. (2013). The disappearing childhood of children's literature studies. Jeunesse: Young People, Texts, Cultures, 5(1):149-163. https://doi.org/10.1353/ jeu.2013.0003

Nodelman, P. (2015). The scandal of the common place. The strangeness of best-selling picturebooks. In J. Evans (Ed.), Challenging and controversial picturebooks. Creative and critical responses to visual texts (pp. 3348). Routledge.

Nodelman, P. y Reimer, M. (2003). The pleasures of children's literature. Allyn and Bacon.

O’Neil, K. E. (2011). Reading pictures: Developing visual literacy for greater comprehension. The Reading Teacher, 65(3), 214-223. https://doi.org/10.1002/ TRTR.01026

Pantaleo, S. (2004a). Young children and radical change characteristics in picture books. The Reading Teacher, 58(2), 178-187. https://doi.org/10.1598/ RT.58.2.6
Pantaleo, S. (2004b). Young children interpret the metafictive in Anthony Browne's Voices in the Park. Journal of Early Childhood Literacy, 4(2), 211-233. https:// doi.org/10.1177/1468798404044516

Pantaleo, S. (2007). Interthinking: Young children using language to think collectively during interactive read-alouds. Early Childhood Education Journal, 34, 439-447. https://doi.org/10.1007/ s10643-007-0154-y

Pantaleo, S. (2010). Developing narrative competence through reading and writing metafictive texts. $\mathrm{Li}$ teracy Research and Instruction, 49(3), 264-281. https://doi.org/10.1080/19388070903100324

Pantaleo, S. (2015). Primary students' understanding and appreciation of the artwork in picturebooks. Journal of Early Chidhood Literacy, 16(2), 228-255. https:// doi.org/10.1177/1468798415569816

Pantaleo, S. (2016). Critical thinking and young children's exploration of picturebook artwork. Language and Education, 31(2), 152-168. https://doi.org/10.108 $0 / 09500782.2016 .1242599$

Parsons, E. (2011). Ideology. In P. Nel y L. Paul (Eds.), Keywords for children's literature (pp. 113-116). New York University Press.

Prior, L. A., Willson, A. y Martinez, M. (2012). Picture this: Visual literacy as a pathway to character understanding. The Reading Teacher, 66(3), 195-206. https:// doi.org/10.1002/TRTR.01098

Ridley, D. (2012). The literature review. A step-by-step guide for students. Sage.

Riggio, M. M. y Cassidy, K. W. (2009). Preschoolers' processing of false beliefs within the context of picture book reading. Early Education and Development, 20(6), 992-1015. https://doi. org/10.1080/10409280903375685

Rose, J. (1984). The case of Peter Pan, or the impossibility of children's fiction. Macmillan. https://doi. org/10.1007/978-1-349-17385-3

Rosenblatt, L. M. (1993). The transactional theory: Against dualisms. College English, 55(4), 377-386. https:// doi.org/10.2307/378648

Rudd, D. (2004). Theorising and theories: The conditions of possibility of children's literature. En P. Hunt (Ed.), International companion encyclopedia of children's literature. Routledge.

Sánchez-Eppler, K. (2011). Childhood. In P. Nel y L. Paul (Eds.), Keywords for children's literature (pp. 35-41). Routledge. 
Serafini, F. (2003). Informing our practice: Modernist, transactional, and critical perspectives on children's literature and reading instruction. Reading Online, 6(6):1-15. https://www.researchgate.net/ publication/289874920_Informing_our_practice_Modernist_transactional_and_critical_perspectives_on_children\%27s_literature_and_reading_instruction

Serafini, F. (2005). Voices in the park, voices in the classroom: Readers responding to postmodern picture books. Reading Research and Instruction, 44(3), 4764. https://doi.org/10.1080/19388070509558431

Sipe, L. y McGuire, C. (2006). Young children's resistance to stories. The Reading Teacher, 60(1), 6-13. https:// www.jstor.org/stable/20204428

Sipe, L. y Pantaleo, S. (2008). Introduction. Postmodernism and picturebooks. En L. Sipe and S. Pantaleo (Eds). Postmodern picturebooks: Play, parody, and self-referentiality (pp. 1-8). Routledge.

Smith, R. (1995). Young children's interpretations of gender from visual text and narrative. Linguistics and Education, 7(4), 303-325. https://doi. org/10.1016/0898-5898(95)90007-1

Styles, M. y Arizpe, E. (2001). A gorilla with "Grandpa's eyes": How children interpret visual texts-A case study of Anthony Browne's “Zoo”. Children's Literature in Education, 32, 261-281. https://doi. org/10.1023/A:1012760422501

Styles, M. y Arizpe, E. (2004). Lectura de imágenes. Los niños interpretan textos visuales. Fondo de Cultura Económica.

Unsworth, L. y Macken-Horarik, M. (2015). Interpretive responses to images in picture books by primary and secondary school students: Exploring curricu- lum expectations of a "visual grammatics". English in Education, 49(1), 56-79. https://doi.org/10.1111/ eie. 12047

Van der Pol, C. (2012). Reading picturebooks as literature: Four-to-six-year-old children and the development of literary competence. Children's Literature in Education, 43, 93-106. https://doi.org/10.1007/ s10583-011-9149-9

Walker, C. M., Gopnik, A. y Ganea, P. (2015). Learning to learn from stories: Children's developing sensitivity to the causal structure of fictional worlds. Child Development, 86(1), 310-318. https://doi. org/10.1111/cdev.12287

Watson, V. y Styles, M. (1996). Talking pictures: Pictorial texts and young readers. Hodder \& Stoughton.

Waxman, S., Hermann, P., Woodring, J. y Medin, D. (2014). Humans (really) are animals: Picture-book reading influences 5-year-old urban children's construal of the relation between humans and non-human animals. Frontiers in Psychology, 5. https://doi. org/10.3389/fpsyg.2014.00172

Whitelaw, J. (2017). Beyond the bedtime story: In search of epistemic possibilities and the innovative potential of disquieting picturebooks. Bookbird: A Journal of International Children's Literature, 55(1), 33-41. https://doi.org/10.1353/bkb.2017.0004

Yang, C. C. R. (2016). Are males and females still portrayed stereotypically? Visual analyses of gender in two Hong Kong primary English language textbook series. Gender and Education, 28(5), 674-692. https:// doi.org/10.1080/09540253.2015.1103839

Zipes, J. (2001). Sticks and stones: The troublesome success of children's literature from slovenly Peter to Harry Potter. Routledge.

Cómo citar este artículo: Véliz, S. (2022). Los libros álbum radicales en contextos educativos: una revisión sistemática sobre propósitos, competencias y relaciones entre mediadores y lectores. Íkala, Revista de Lenguaje y Cultura, 27(1), 199-223. https://doi.org/10.17533/udea.ikala.v27n1a10 